\title{
DEMOCRACIA NA ESCOLA: POSSIBILIDADES E DESAFIOS
}

\author{
Márcia Aparecida Jacomini ${ }^{1}$ \\ Cileda dos Santos Sant'Anna Perrella ${ }^{2}$ \\ Marieta Gouvêa de Oliveira Penna ${ }^{3}$ \\ Isabel Melero Bello ${ }^{4}$
}

JACOMINI, M. A.; PERELlA, C. dos S. S.; PENNA, M. G. de O.; BELLO, I. M. Democracia na escola: possibilidade e desafios. EDUCERE - Revista da Educação, Umuarama, v. 19, n. 1, p. 195-219, jan./jun. 2019.

RESUMO: A gestão democrática da escola pública alçou status de princípio constitucional após muita luta e certo consenso de que uma sociedade democrática se faz com base numa educação democrática. Contudo, muitas vezes, a ideia e a prática de gestão democrática nas escolas públicas de educação básica, bem como nas instituições de ensino superior, ficaram restritas a um funcionamento formal das instâncias estabelecidas. Este artigo, cujos dados e análises advém de um projeto de extensão, tem como objetivo discutir o processo e os resultados de pesquisa numa escola da rede estadual de ensino de São Paulo. Trata-se de pesquisa-ação, na qual as práticas escolares têm sido objeto de problematização, com a finalidade de contribuir para democratização da organização e do funcionamento da escola. As análises foram realizadas a partir dos registros produzidos nos encontros mensais ocorridos na escola. Como referência teórica, foram mobilizados autores que discutem o conceito de democracia, e as possibilidades de sua realização na escola. Também, autores que discutem a escola como instituição social. O exercício de reflexão,

DOI: $10.25110 /$ educere.v19i1.2019.6995

${ }^{1}$ Doutora em Educação pela Faculdade de Educação da Universidade de São Paulo. Professora Associada do Departamento de Educação da Escola de Filosofia, Letras e Ciências Humanas da Universidade Federal de São Paulo. E-mail: jacominimarcia@gmail.com

${ }^{2}$ Doutora em Educação pela Faculdade de Educação da Universidade de São Paulo. Professora e coordenadora do curso de Pedagogia da Faculdade Zumbi dos Palmares. E-mail: cileda.perrella@ gmail.com

${ }^{3}$ Doutora em Educação pela Pontifícia Universidade Católica de São Paulo. Professora Associada do Departamento de Educação da Escola de Filosofia, Letras e Ciências Humanas da Universidade Federal de São Paulo. E-mail: marieta.penna@yahoo.com.br

${ }^{4}$ Doutora em Educação pela Faculdade de Educação da Universidade de São Paulo. Professora do Departamento de Educação da Escola de Filosofia, Letras e Ciências Humanas da Universidade Federal de São Paulo. E-mail: isabel_bello@yahoo.com.br 
envolvendo estudo e discussão, propiciou percepções e questionamentos sobre em que medida a comunidade escolar pauta suas ações cotidianas em princípios democráticos e suscitou mudanças nas práticas educativas. PALAVRAS-CHAVE: Democracia; Educação Básica; Escola Pública; Gestão Democrática.

\section{DEMOCRACY AT SCHOOL: POSSIBILITIES AND CHALLENGES}

ABSTRACT: The democratic management of the public school has reached the status of a constitutional principle after much struggle and a certain consensus that a democratic society is based on democratic education. However, the idea and practice of democratic management in public basic schools, as well as in higher education institutions, is often restricted to a formal functioning of the established entities. This article, whose data and analysis come from an extension project, aims at discussing the research process and results in a school from the state education network of São Paulo. This is an action research, where school practices have been object of problematization, with the purpose of contributing to the democratization of the organization and functioning of the school. The analyzes were carried out from the records produced in the monthly meetings held at the school. Authors that discuss the concept of democracy were used as theoretical reference, analyzing the possibilities of implementing them at schools, as well as analyzing authors who discuss school as a social institution. The reflection exercise involving study and discussion provided insights and raises questions about the extent to which the school community performs its daily actions on democratic principles and led to changes in educational practices.

KEYWORDS: Democracy; Basic Education; Public School; Democratic Management.

\section{DEMOCRACIA EN LA ESCUELA: POSIBILIDADES Y DESAFÍOS}

RESUMEN: La gestión democrática de la escuela pública alcanzó la condición de principio constitucional tras mucha lucha y cierto consenso de que una sociedad democrática se hace sobre la base de una educación 
democrática. Sin embargo, a menudo, la idea y la práctica de gestión democrática en las escuelas públicas de educación básica, así como en las instituciones de enseñanza superior, quedaron restringidas a un funcionamiento formal de las instancias establecidas. Este artículo, cuyos datos y análisis provienen de un proyecto de extensión, tiene como objetivo discutir el proceso y los resultados de investigación en una escuela de la red estatal de enseñanza de São Paulo. Se trata de investigación y acción, en la cual las prácticas escolares han sido objeto de problematización, con la finalidad de contribuir a la democratización de la organización y del funcionamiento de la escuela. Los análisis se realizaron a partir de los registros producidos en los encuentros mensuales ocurridos en la escuela. Como referencia teórica, fueron movilizados autores que discuten el concepto de democracia, y las posibilidades de su realización en la escuela. También, autores que discuten la escuela como institución social. El ejercicio de reflexión, involucrando estudio y discusión, propició percepciones y cuestionamientos sobre en qué medida la comunidad escolar pauta sus acciones cotidianas en principios democráticos y suscitó cambios en las prácticas educativas.

PALABRAS CLAVE: Democracia; Educación Básica; Escuela Pública; Gestión Democrática.

\section{INTRODUÇÃO}

A democracia pode ser entendida como forma de organização da sociedade, tanto em termos institucionais, como em relação à convivência social. Nas sociedades modernas, ela tem sido compreendida como elemento importante para a organização política na maioria dos países, embora carregada de significados diversos. Do ponto de vista teórico e conceitual ela se opõe ao autoritarismo, à ditadura ou à autocracia.

Como parte da superestrutura, as instâncias de exercício da democracia guardam estreitas relações com a infraestrutura, isto é, com a forma de produção material da sociedade, no caso da nossa, o modo de produção capitalista. Assim, ela é delineada pelos condicionantes e determinantes da reprodução material, moldada por estruturas e formas de organização corresponsáveis pela manutenção do status quo. Como afirma Coutinho (2000, p. 129), "uma verdadeira democracia é um processo que implica não só modificações políticas, mas também modificações econô- 
micas e sociais".

Pontuamos os limites das práticas democráticas em nossa sociedade, não apenas pelas características históricas, culturais e de formação política da população, mas também pelos condicionantes que operam por meio da desigualdade econômica, decorrente da forma como capital e trabalho se reproduzem. Não estamos recorrendo aos limites para justificar as dificuldades que encontramos em níveis micro e macro para o estabelecimento, o fortalecimento e a manutenção de instâncias e práticas democráticas, mas para indicar a necessidade de forçar a dilatação destas. Atuar na perspectiva de avançar na democratização da sociedade.

A democratização da sociedade como valor e a realização de práticas democráticas demandam a educação política da população (BENEVIDES, 1994), requerem esforço permanente, reflexão e vigília constantes sobre o ser, o pensar e o agir individuais e coletivos, e exigem a criação de espaços para isso.

A compreensão de que o exercício da democracia pressupõe, além de instâncias institucionais democráticas, indivíduos imbuídos de um "espírito democrático", que os comprometa a defendê-la como forma de organização social e de convivência, leva aos seguintes questionamentos: o que significa educar para a democracia? Como educar por meio de práticas democráticas?

Esses questionamentos nortearam o desenvolvimento de pesquisa-ação ${ }^{5}$ que teve por objetivo a concretização de ações colaborativas de estudo e reflexão sobre democracia, com vistas à construção de práticas educativas democráticas numa escola da rede estadual de ensino de São Paulo $^{6}$, situada no município de Guarulhos. Tal investigação ocorreu mediante a realização de projeto de extensão que tem como pressuposto a formação para e pela democracia.

Como expresso por Giovanni (2009, p. 55), compreendemos ser possível e importante o estabelecimento de trabalho conjunto entre a es-

\footnotetext{
5"Trata-se de pesquisas nas quais há uma ação deliberada de transformação da realidade; pesquisas que possuem um duplo objetivo: transformar a realidade e produzir conhecimentos relativos a essas transformações". (HUGON; SEIBEL, 1988 apud BARBIER, 2007, p. 17).

${ }^{6} \mathrm{~A}$ escola onde a pesquisa foi realizada atende em torno de 1.000 alunos, funciona em dois turnos (manhã e tarde), a equipe gestora é composta por diretor, vice-diretor e coordenador pedagógico, trabalham na escola anualmente em aproximadamente 60 professores e 12 agentes escolares. Como a pesquisa foi realizada em mais de um ano optamos por informar os números aproximados à medida que há pequena variação de um ano para outro.
} 
cola pública de educação básica e a universidade a fim de se construir alternativas à situação "considerada insatisfatória, merecedora de estudos e investigação para a busca de soluções e mudanças". Por um lado, intentamos contribuir para o aprimoramento de relações democráticas na escola. Por outro, colaborar com o debate sobre as dificuldades e possibilidades de estabelecimento de práticas democráticas na escola.

Nosso objetivo, neste artigo, é apresentar análises e resultados do projeto de extensão, no formato de pesquisa-ação, entre os anos de 2016 e 2018 e indicar algumas mudanças observadas na forma de pensar e praticar a democracia no contexto escolar. As análises foram realizadas a partir dos registros produzidos nos encontros mensais ocorridos na escola, que contaram com a participação de professoras da Universidade Federal de São Paulo, equipe gestora da escola, professores, alunos e agentes escolares.

O texto está dividido em três tópicos, além desta introdução. No primeiro, apresentamos alguns pressupostos teóricos que têm embasado nossas reflexões e ações na escola. No segundo, analisamos o processo de realização do projeto, com foco nas reflexões e práticas. Nas considerações finais, destacamos alguns resultados e a continuidade do projeto.

\section{GESTÃO DEMOCRÁTICA DA ESCOLA PÚBLICA: ASPECTOS LEGAIS E PRÁTICOS}

A gestão democrática da escola pública alçou status de princípio constitucional (BRASIL, 1988) após muita luta e certo consenso de que uma sociedade democrática se faz com base numa educação democrática (CAMARGO, JACOMINI, GOMES, 2016). Contudo, muitas vezes, a ideia e a prática de gestão democrática nas escolas públicas de educação básica, bem como nas instituições de ensino superior, ficam restritas ao funcionamento formal das instâncias estabelecidas (PARO, 2007; ARELARO, JACOMINI, CARNEIRO, 2016, 2016, entre outros). Predomina assim a constituição de espaços com ações pautadas pelo gerencialismo e pelo hierarquismo quanto aos encaminhamentos e às tomadas de decisões coletivas, em detrimento do exercício de seu caráter político (DOURADO, 2007; ADRIÃO; PERONI, 2007).

De acordo com a Lei de Diretrizes e Bases da educação nacio- 
nal (LDB/96) (BRASIL, 1996), os sistemas de ensino devem definir as normas de gestão democrática, tendo por base os seguintes princípios: participação dos profissionais da educação na elaboração do projeto pedagógico e participação da comunidade escolar e local em conselhos escolares ou equivalentes ${ }^{7}$.

A partir dessa determinação legal, as escolas públicas, com base em normas e orientações dos sistemas de ensino, imprimem formas de participação nos processos de elaboração e decisão acerca do projeto educativo, seja pelo dever de cumprimento normativo, seja pela compreensão de que a participação da comunidade escolar é elemento fundante da gestão democrática.

No primeiro caso, talvez o mais comum, trata-se de prática formal de democracia, opera-se a partir de acordo tácito sobre o que deve ser feito, abdica-se de discutir as divergências, de refletir sobre diferenças, de construir consensos. Em síntese, esconde-se a pluralidade sob um suposto consenso, posto que participar, discutir, convencer e ser convencido exigem dedicação, esforço e a compreensão de que isso é processo educativo.

No segundo, busca-se, a partir de diversos meios e instâncias, a instituição de processos participativos. Acredita-se que a gestão democrática da escola resguarda estreita relação com uma concepção de educação na qual os indivíduos ali implicados são sujeitos de vontade, com poder de decisão (PARO, 2011).

A CF/1988 e a LDB/1996, ao trazerem a gestão democrática como um importante princípio da educação institucionalizada, convidam-nos a refletir sobre a importância da democratização das relações estabelecidas nessa instituição, visando à superação de práticas pautadas pelo autoritarismo e a verticalização presentes no cotidiano da escola e dos sistemas de ensino. Isso traz implicações para o processo educativo que se desenvolve nesse espaço a partir de um intrincado de relações de poder estabelecidas não apenas entre professores e alunos, mas que perpassam por todos aqueles que direta ou indiretamente atuam na escola, bem como no sistema escolar, para que o fim da educação seja alcançado, qual seja:

\footnotetext{
${ }^{7}$ Ressaltamos aqui que não consideramos instâncias colegiadas como as Associações de Pais e Mestres (APM) que historicamente se firmaram como espaço de arrecadação financeira junto às famílias, como equivalentes aos Conselhos de Escola (CE), estes reconhecidos com caráter político na tomada de decisões da escola na CF/1988, na LDB/1996 e no PNE/2001 e 2014.
} 
o aluno educado.

Com base no conceito de gestão como escolha e utilização racional de meios para se atingir determinado objetivo, e compreendendo que os meios não podem ser contraditórios aos fins (PARO, 2011), a gestão da escola pública ${ }^{8}$ é qualificada nos documentos legais como democrática. Se o objetivo da educação básica é a formação integral das crianças, adolescentes e jovens, estando estes em processo formativo, as tomadas de decisões que dizem respeito à garantia de seus direitos necessariamente devem se dar por meio de práticas democráticas em que todos são importantes e participam ativamente do processo educativo: alunos, professores, equipe gestora, famílias, tarefa nem sempre de fácil realização nas escolas. Sobre os desafios da participação, Freire (2001) afirma que sua efetivação está em relação direta com uma prática educativa progressista, que compreenda o exercício da dúvida, da crítica, e na qual todos sejam ouvidos.

O autor chama atenção para a perversidade da inibição parcial ou total da participação, o que interfere diretamente no processo de sua democratização. Por isso, considera uma contradição um processo educativo em que os envolvidos não sejam sujeitos de sua ação, com direito à voz e voto, seja por meio dos espaços democráticos legalmente constituídos, ou em espaços construídos pela própria escola, não cabendo a tutela em processos participativos que demandam tomadas de decisões, que possibilitam aprendizagens, ou inibição da participação de qualquer segmento da comunidade escolar no tocante a decisões relativas aos interesses coletivos (PARO, 2008; FREIRE, 1993, 2001).

A democratização das relações estabelecidas no espaço escolar requer a consideração da escola como grupo social, sendo necessário compreender a estrutura da escola que, de acordo com Cândido (1974), envolve não somente as prescrições legais, mas a totalidade das relações sociais que ali se desenvolvem.

A diversidade de relações presentes no cotidiano escolar traz no seu bojo a importância do debate sobre a democratização desse espaço educativo, uma vez que os diferentes segmentos da comunidade escolar (alunos, professores, gestores, pais e responsáveis) podem apresentar

\footnotetext{
${ }^{8}$ Como fruto de debates e embates entre, por um lado donos de escolas particulares, filantrópicas, confeccionais, por outro dos movimentos sociais defensores da educação como direito de todos, o termo Gestão Democrática, art. $5^{\circ}$ ficou restrito à escola pública (CAMARGO; ADRIÃO, 2002).
} 
expectativas diferenciadas, constituindo desafio à comunidade escolar, construir de forma democrática e participativa os consensos em torno do projeto educativo. Esse processo pode contribuir para a identificação das concepções de educação e de escola existentes, aspecto relevante às práticas democráticas por parte de todos.

Como grupo institucionalizado, a escola é "produto da cooperação de seus próprios membros" (CÂNDIDO, 1974, p. 109), estando sujeita a receber influências de outros grupos sociais (políticos, religiosos, de classe, gênero, étnicos, etários, entre outros) que perpassam por seu cotidiano, marcando de forma contundente sua cultura, o estabelecimento de um sistema de normas e valores para a instituição.

Nessa perspectiva, "sua dinâmica interna dá lugar a formações específicas, mantidas por um sistema de normas e valores também internamente desenvolvidos" (CÂNDIDO, 1974, p. 109), o que pode ter elementos que afastam a comunidade externa - como, por exemplo, os familiares dos estudantes - da tomada de decisões dos rumos da escola, chamados para participar apenas do que a escola considera caber prioritariamente às suas responsabilizações (PEREIRA, 1967). “A escola apresenta uma ordenação racional evidenciada no ensino e na gestão, que acaba por ordenar o ajustamento dos padrões de sociabilidade, por exemplo, dos educandos aos dos educadores, atores centrais de sua ação" (PERRELLA, 2012, p. 119)

Ampliando o debate sobre a estrutura da escola, Paro (2011), afirma que para a democratização das relações nela estabelecidas, a preocupação não deve se restringir às demandas tomadas de forma isolada, posto envolverem a partilha de poder, sendo importante a participação de todos na gestão, evitando-se assim relações de poder de uns sobre outros.

Por isso, é fundamental que no processo educativo todos os envolvidos sejam reconhecidos como sujeitos de vontade e com poder de decisão, num esforço de aproximação ao destacado por Freire (1993), isto é, que somos seres inacabados, aprendentes da prática democrática.

Na prática educativa num grupo social como a escola, em que todos se afirmam como sujeitos, o empoderamento deve ser coletivo, o que se constitui em inegável ganho para todos e para o processo educativo que os envolve e para a transformação das relações autoritárias presentes no cotidiano escolar. 
Cabe ainda destacar, ao discutirmos a democratização das relações estabelecidas na escola, que partimos de entendimento que a educação escolar envolve tanto a instrução quanto a formação, tomadas de forma unitária (GRAMSCI, 2011). Não se trata, portanto, de opor uma à outra. A escola educa na medida em que instrução e formação ${ }^{9}$ se fundem numa prática entre sujeitos em posições diferentes e desempenhando papeis específicos. Nesse sentido, a relação de assimetria entre educador e educando não deve implicar em autoritarismo e submissão, mas ser resultante da especificidade do papel de cada um no contexto escolar.

O processo educativo pressupõe diálogo, relações de respeito e de implicação voluntária, portanto, não pode ser ato impositivo. Com isso, não estamos advogando o descomprometimento do adulto para com a educação das crianças e jovens, como nos alertou Arendt (2009), mas destacando que a educação, no sentido em que a apropriação de conhecimentos e valores seja por convencimento e não por imposição, requer necessariamente práticas democráticas, o que implica considerar o envolvimento de sujeitos com poder de decisão. Assim, a democracia atua como um pressuposto desse tipo de educação.

\section{REFLEXÕES SOBRE DEMOCRACIA QUE CONTRIBUEM PARA A MUDANÇA DE PRÁTICAS AUTORITÁRIAS: O DESEN- VOLVIMENTO DO PROJETO}

Para o desenvolvimento de projeto de extensão, que envolve estudo e reflexão sobre democracia e construção de práticas educativas democráticas na escola, iniciamos diálogo com gestores de uma escola da rede estadual de ensino de São Paulo no ano de 2014. Como nosso propósito era desenvolver uma pesquisa-ação, de forma que a realidade escolar pudesse ser problematizada e modificada, era fundamental que a escola manifestasse disponibilidade em discutir de forma crítica suas práticas, teorias e culturas.

A escola escolhida tem parceria com a Universidade Federal de

${ }^{9}$ De acordo com Gramsci (2011, p. 44) "para que a instrução não fosse igualmente educação, seria preciso que o discente fosse uma mera passividade, um 'recipiente mecânico' de noções abstratas, o que é absurdo, além de ser 'abstratamente' negado pelos defensores da pura educatividade precisamente contra a mera instrução mecanicista. 
São Paulo (Unifesp) para o desenvolvimento do Programa de Residência Pedagógica ${ }^{10}$ e é conhecida na região por ter uma equipe gestora que preza pela gestão democrática e pela participação nas atividades de luta da categoria docente. Embora as conversas iniciais tenham sido realizadas no final de 2014, no primeiro semestre de 2015 não conseguimos avançar na elaboração conjunta do projeto, porque houve 92 dias de greve na rede estadual e a escola participou deste movimento. Após a greve, ela se voltou integralmente ao processo de reposição das aulas, o que limitou sua disponibilidade para continuidade da construção do projeto.

Quando finalmente as conversas foram retomadas em meados do segundo semestre de 2015, teve início a ocupação das escolas estaduais pelos estudantes, como forma de luta contra a proposta de reorganização da rede estadual de ensino, que envolvia o fechamento e a divisão das escolas em Ensino Fundamental I, Ensino Fundamental II e Ensino Médio (CAMPOS; MEDEIROS; RIBEIRO, 2016). Assim, mesmo esta escola não estando na lista daquelas que seriam reorganizadas, e não tendo sido ocupada pelos estudantes, esteve intensamente envolvida nos debates sobre a questão. As conversas sobre o projeto foram retomadas somente no início de 2016, após um projeto inicial ter sido submetido à avaliação da Pró-Reitoria de Extensão e Cultura da Unifesp. Dessa forma, a ideia inicial de construir o projeto coletivamente foi parcialmente inviabilizada sendo que a discussão com professores, agentes escolares e estudantes ocorreu com base numa proposta já formulada e poucas modificações foram realizadas após debate com a comunidade escolar.

Um grupo de professores, estudantes, agentes escolares e equipe gestora, que contou com a participação do supervisor escolar ${ }^{11}$, integraram as atividades do projeto coordenadas por professoras e estudantes da Unifesp - campus Guarulhos. No primeiro ano de sua realização, diante da impossibilidade de conciliar a disponibilidade de horário de todos, privilegiou-se atender as demandas dos estudantes, professores e agentes escolares, considerando serem sujeitos essenciais para a implementação do projeto. Por isso, os encontros mensais, que tiverem início no período noturno, após o término das aulas, passaram, no terceiro mês do projeto, a serem realizados durante o horário das atividades escolares, o que difi-

\footnotetext{
${ }^{10}$ Estágio desenvolvido no curso de Pedagogia da Unifesp como parte das atividades promovidas para a formação dos futuros pedagogos.

${ }^{11} \mathrm{O}$ supervisor de ensino participou das atividades somente no primeiro semestre de 2016.
} 
cultou a participação dos pais ${ }^{12}$.

Em 2016, foram realizados 13 encontros entre a universidade e a escola com participação de em torno de 30 pessoas em cada um. A integração de toda a comunidade escolar num processo de reflexão e problematização das práticas autoritárias na escola foi realizada pelos integrantes do projeto, ou seja, aqueles que participaram dos encontros de estudo e reflexão da prática ${ }^{13}$.

Após discussão sobre os objetivos do projeto e a forma de desenvolvimento com este coletivo, decidimos estudar o texto "Cidadania e Democracia" (BENEVIDES, 1994). Dividimos o texto em partes e cada grupo, composto por professores, estudantes e agentes escolares, ficou responsável pela apresentação de uma parte do conteúdo. Essa atividade permitiu algumas reflexões sobre a democracia no Brasil e acerca dos elementos fundamentais às práticas democráticas. $\mathrm{O}$ envolvimento da equipe, nesta atividade, foi diferenciado, uma vez que, como ressaltado por Cândido (1974), os integrantes do grupo escola apresentam expectativas diferenciadas, revelando repercussões da dinâmica interna da escola, mas cabe destacar que para muitos se constituiu em momento importante de estudo e compartilhamento, expresso na forma cuidadosa como os grupos apresentaram a parte do texto pela qual ficaram responsáveis.

Dessas reflexões iniciais, surgiu a ideia de construirmos um conceito de democracia para orientar os debates e práticas da comunidade escolar. Essa atividade envolveu o levantamento dos aspectos que o conceito de democracia deveria contemplar, o que permitiu a organização dos pressupostos do conceito de democracia que foi sistematizado pela equipe da universidade. O grupo considerou que seria importante que o texto formulado passasse por uma leitura crítica de um professor da área da Filosofia. Após os comentários do referido professor ${ }^{14}$, o conceito foi

\footnotetext{
${ }^{12}$ Durante os dois anos do projeto não conseguimos avançar em relação à participação dos pais e responsáveis, foram poucos os encontros em que estiveram presentes.

${ }^{13}$ Embora o projeto envolva toda a comunidade escolar, apenas um grupo de estudantes, professores e agentes escolares participam dos encontros de estudo. O convite para participar dos encontros do projeto foi feito a todos os membros da comunidade escolar e a participação foi por livre iniciativa. Este grupo tem a tarefa de replicar as discussões e reflexões sobre democracia na escola com o conjunto da comunidade escolar nas diferentes atividades que são desenvolvidas no cotidiano escolar, de forma que todos participem do projeto, mesmo que de forma diferenciada.

${ }^{14} \mathrm{~A}$ leitura crítica e sugestões foram realizadas por Denilson Cordeiro, professor de Filosofia de Unifesp - Campus Diadema. As sugestões do professor foram muito importantes para o aprimoramento do conceito.
} 
reformulado com a seguinte redação:

Democracia é uma forma de governar com base na participação direta e/ou representativa dos cidadãos nas diferentes instituições e instâncias da sociedade civil e política, onde são tomadas decisões relativas às questões públicas. A participação democrática pressupõe informações e conhecimentos dos assuntos em deliberação, de forma que os cidadãos possam apresentar posições, com o objetivo de convencer os coparticipantes, assim como apresentar disponibilidade de ser convencido. As propostas a serem deliberadas devem refletir direitos e conhecimentos historicamente construídos que contribuam para a igualdade e a justiça social. $\mathrm{Na}$ ausência de consenso, após amplo debate e esforço de entendimento acerca do melhor encaminhamento, as decisões serão tomadas com base na vontade da maioria.

Esse processo desencadeou uma série de questionamentos sobre a vida escolar, especialmente, por parte dos estudantes, que passaram a indicar práticas escolares que julgavam antidemocráticas, por exemplo, a forma de avaliação por parte de alguns docentes, e reivindicaram discutir os critérios que pautam as avaliações escolares. Também os professores iniciaram reflexões sobre o quanto suas ações eram democráticas. Os agentes escolares tiveram a oportunidade de apresentar um conjunto de sugestões acerca do funcionamento da escola, conquanto, a partir do segundo semestre, deixaram de participar dos encontros, alegando que após as reuniões tinham que dar conta dos seus afazeres num tempo mais curto, o que exigia maior intensidade na realização do trabalho. Novamente recorrendo a Cândido (1974), vemos o surgimento de ações, reações, manifestações que escapam a ordenação racional da escola. A participação desse quadro de funcionárias que parecia, em certa medida, "óbvia” por fazer parte do grupo total interno da escola, não se confirmou, suscitando reflexões sobre as motivações de tal posicionamento. Isso dificultou o envolvimento deste segmento da comunidade escolar na implementação do projeto, embora continuassem envolvidos num clima de ação-reflexão-ação de democracia na escola. 
Dados os objetivos e o uso da metodologia da pesquisa-ação (BARBIER, 2007), a realização do projeto depende do envolvimento da comunidade escolar, o que demandou esforços constantes tanto para manutenção do grupo na realização dos encontros, quanto da ação dele junto aos pares para que as discussões ali realizadas fossem socializadas e pudessem orientar as práticas.

Para orientar o debate sobre as práticas educativas da escola, tomamos como referência a leitura e discussão do texto "O argumento por escolas democráticas" (APPLE; BEANE, 2001) e o grupo debruçou-se a verificar em que medida as condições essenciais às práticas democráticas apresentadas pelos autores estavam presentes na escola. As condições são:

O livre fluxo das ideias, independentemente de sua popularidade, que permitem às pessoas estarem tão bem informadas quanto possível.

Fé na capacidade individual e coletiva de as pessoas criarem condições de resolver problemas.

O uso da reflexão e da análise crítica para avaliar ideias, problemas e políticas.

Preocupação com o bem-estar dos outros e o "bem comum".

Preocupação com a dignidade e os direitos dos indivíduos e das minorias.

A compreensão de que a democracia não é tanto um "ideal" a ser buscado, como um conjunto de valores "idealizados" que devemos viver e que devem regular nossa vida enquanto povo.

A organização de instituições sociais para promover e ampliar o modo de vida democrático. (APPLE; BEANE, 2001, p. 17)

Para esse debate, utilizamos a dinâmica de discussão em pequenos grupos e socialização posterior. Essa dinâmica foi reivindicada pelos participantes à medida que possibilita que todos possam apresentar sua forma de pensar as questões em discussão, o que nem sempre ocorre quando o debate é feito diretamente pelo conjunto dos participantes dos encontros. 
A discussão nos pequenos grupos permitiu observar semelhanças e diferenças nas percepções e compreensões dos participantes, sendo comum os estudantes terem um olhar mais atento às práticas não democráticas, o que causou certo desconforto, por parte de alguns professores, quando foram apresentadas ao conjunto dos participantes. Os alunos questionaram a forma como certas aulas eram estruturadas, indicando que elas não contribuíam para uma boa aprendizagem, a falta de uso do laboratório de informática e reivindicaram que os professores abordassem as questões de gênero e sexualidade nas aulas. Observa-se que, quando ouvidos, os alunos trazem questões contrárias ao que propõe o Movimento Escola sem Partido e que polarizou a discussão de gênero nos planos estaduais e municipais de educação, assim como a Base Nacional Comum Curricular ${ }^{15}$.

Desse processo resultou a indicação do que o coletivo considerava necessário modificar para melhorar as práticas democráticas na escola, expressa na seguinte síntese.

- Melhorar o fluxo de informação: os estudantes ainda não compreendem muito bem os critérios de avaliação e os projetos desenvolvidos na escola;

- Há pouca tolerância em relação às ideias conservadoras na escola;

- Precisamos melhorar nossa crença e confiança na capacidade das pessoas e do coletivo resolverem os problemas;

- A reflexão crítica tem sido usada nas relações entre pares, mas menos usada nas relações entre os segmentos e o coletivo escolar;

- A preocupação com o bem comum está presente no coletivo, mas nem todos os membros da comunidade escolar têm o bem comum como um pressuposto da convivência coletiva no

\footnotetext{
${ }^{15}$ O Projeto de Lei 7.180/2014 que tramita na Câmara dos Deputados apresenta a proposta de alterar o art. $3^{\circ}$ da Lei n ${ }^{\circ}$ 9.394/96, Lei de Diretrizes e Bases da Educação Nacional, para incluir como princípio do ensino "o respeito às convicções do aluno, de seus pais ou responsáveis, dando preferência aos valores de ordem familiar sobre a educação escolar nos aspectos relacionados à educação moral, sexual e religiosa". Disponível em: http://www.camara.gov.br/proposicoesWeb/fi chadetramitacao?idProposicao=606722 Acesso 25 ago. 2018. Para saber mais sobre o tema ler "A ideologia do movimento Escola sem Partido: 20 autores desmontam o discurso", São Paulo: Ação Educativa, 2016.
} 
espaço escolar;

- Observa-se ainda certo descompasso entre um discurso democrático e uma prática nem sempre correspondente, o desenvolvimento do projeto tem sido uma oportunidade de refletir sobre isso;

- Precisamos discutir sobre a participação dos estudantes em suas instâncias de organização, como o grêmio. Tem prevalecido uma ideia e uma prática de que apenas os estudantes com bom desempenho escolar e bem-comportados podem participar de atividades dessa natureza. É fundamental refletir sobre as consequências dessa prática à formação dos estudantes e à democratização da escola.

Destacamos desse conjunto de indicações o descompasso entre discurso e prática e o reconhecimento, por parte dos estudantes mais atuantes nas questões político-pedagógicas da escola, de que há pouco espaço para a expressão das opiniões que não corroboram as convicções desse grupo, o que fere a livre circulação de ideias e desconsidera um dos fundamentos do processo democrático que é o convencimento, conforme destacado no conceito de democracia, construído coletivamente.

Também resultou dessa atividade, a percepção de algumas dinâmicas escolares que contribuem para o desencadeamento de conflitos.

- Os grupos progressistas da escola reconhecem que nem sempre atuam na perspectiva de que todas as posições devem ter espaço para serem expressas, indicando dificuldade de conviver com a pluralidade de ideias.

- Conflitos no relacionamento entre professores e estudantes: parece faltar um pacto entre esses dois segmentos na realização do processo educativo: regras de convivência, forma de ocupar o espaço físico em sala de aula, metodologias de realização do trabalho pedagógico, formação numa perspectiva de autonomia.

- As informações nem sempre circulam a contento, o que corrobora para intensificação de conflitos que poderiam ser minimizados. 
Durante o debate, questões como, entre outras, sobre por que os estudantes precisam pedir autorização ao professor para ir ao banheiro e por que os estudantes têm dificuldade de prestar atenção à aula fizeram com que o grupo reconhecesse a necessidade de se elaborar um Contrato Pedagógico que orientasse a convivência democrática na escola e que melhor traduzisse e detalhasse alguns itens presentes no Regimento Escolar, uma vez que o conteúdo deste ainda parecia engessado, com linguagem formal, pouco claro diante de diversos impasses que exigiam clareza e objetividade nos encaminhamentos a serem adotados.

Os participantes do projeto compreendiam que se tratava de tarefa urgente e que deveria dialogar com o Projeto Político Pedagógico da Escola. Assim, encontrava-se em movimento uma reflexão mais ampla sobre a escola, justamente no momento em que 2016 chegava ao final, impossibilitando que as questões postas pudessem ser tratadas naquele ano, o que indicou a necessidade de continuidade do projeto, aprovada no encontro de avaliação, realizado em dezembro de 2016.

As falas relativas à avaliação do projeto, em seu primeiro ano de vigência, sintetizam em certa medida seu significado, as dificuldades para realizá-lo e seu potencial para proporcionar mudanças nas práticas escolares. Segue uma síntese de algumas das reflexões, sugestões e comentários de estudantes, professores e gestores sobre o projeto.

- Realizamos reflexões e exercícios com vistas a termos atitudes mais democráticas na sala de aula. Mas isso não é fácil;

- O Projeto influência minhas atitudes também fora da escola;

- O Projeto foi uma decisão coletiva. O que conseguimos realizar até o momento foi uma reflexão individual, olhamos para nossas atitudes autoritárias, ainda não avançamos de forma coletiva em práticas mais democráticas;

- A partir do projeto observamos na sala de aula, alunos com mais vontade de discutir temas diversos;

- O projeto foi fundamental para os estudantes repensarem suas práticas. Diferente de anos anteriores, alunos de todos os anos participaram das atividades de mobilização na escola;

- Discutir democracia na escola foi importante, porque nos permitiu combater certa subserviência a qual estamos submetidos 
nos últimos anos em relação à Secretaria Estadual de Educação;

- Começamos a entender como nos relacionarmos com os estudantes em termos democráticos;

- Trabalhar nesta escola me fez uma pessoa com atitudes mais democráticas.

- O Projeto representa uma necessidade incessante de reflexão sobre a prática. Ele nos permite estranhar aquilo que normalmente é visto como "natural";

- Seria importante que a universidade trouxesse mais informação sobre democracia e que os encontros fossem menos maçantes;

- O Projeto precisa chegar à sala de aula. Precisamos discutir com os alunos, refletir coletivamente como construir práticas e relações democráticas;

- Temos como desafio mobilizar nossos colegas, alunos e pais a participarem do Projeto. A direção tem papel importante nisso;

- Precisamos trabalhar o que é liberdade e as relações entre liberdade e democracia;

- Devemos dar continuidade ao projeto.

Percebe-se, a partir dos comentários acima elencados, que não existia uma cultura de participação efetiva nas decisões coletivas, situação comum em ambientes como o escolar. Neste primeiro ano de desenvolvimento do projeto foi ficando mais claro à comunidade escolar os graus e níveis de participação dos quais nos fala Bordenave (1983). Nota-se que até mesmo o menor grau de participação que é a informação, segundo o autor, não contemplava o conjunto da comunidade escolar. Essa percepção foi um passo inicial para a reflexão sobre o significado da participação no processo educativo. Nas palavras de Bordignon (2004, p. 307), "só há efetiva participação e compromisso quando se adquire a cultura do querer participar para exercer poder sobre o que lhe pertence, o que diz respeito à sua vida e ao seu futuro".

O projeto teve continuidade em 2017 com o objetivo de elaborar o Contrato Pedagógico (CP), entendendo-o como um instrumento que, produzido coletivamente, contribuiria para o conjunto da comunidade 
escolar avançar na práxis democrática. A ideia central era que esse documento orientasse, de forma democrática, as relações entre todos, estudantes, professores, gestores e funcionários. Para tanto, sete encontros foram realizados ao longo de 2017 com o grupo envolvido diretamente com o desenvolvimento do projeto e várias atividades com o conjunto da comunidade escolar com vistas a garantir um processo participativo na elaboração das regras e normas que devem orientar uma convivência escolar democrática.

A elaboração do CP ocorreu em quatro momentos distintos, combinando participação na forma da democracia representativa e da democracia direta (BOBBIO, 2000; BORDENAVE, 1983). O grupo que desenvolve o projeto fez inicialmente um levantamento de questões que deveriam ser contempladas no CP. Num segundo momento, essas questões foram debatidas em cada sala de aula e outras foram acrescidas. Uma comissão de estudantes de cada turma fez a sistematização das propostas discutidas e aprovadas nas salas de aulas. Num terceiro momento, as professoras da universidade organizaram as propostas num documento que passou a ser discutido pelos participantes diretos do projeto, que formularam uma proposta de $\mathrm{CP}$, considerando as propostas apresentadas e debatidas nos momentos anteriores. Nova comissão de estudantes e professores foi formada para redigir o texto do $\mathrm{CP}$, que foi submetido, num quarto momento, à discussão e à aprovação em assembleia com participação de estudantes, professores, gestores e funcionários. Alguns itens da proposta de CP foram modificados na assembleia, realizada em outubro de 2017, com importante protagonismo dos estudantes. O CP foi apresentado aos pais em reunião de Pais e Mestre no final daquele ano.

Nos encontros, os participantes foram incentivados a apresentar questões que afetavam negativamente a prática da democracia na escola. De forma tímida no início, as falas foram surgindo e ao final dos encontros a maioria dos participantes desejava expressar suas ideias. Nesse processo, foi perceptível maior participação e manifestações dos alunos do Ensino Fundamental. Se no início do projeto a voz dos estudantes era predominantemente representada por jovens do Ensino Médio, com o passar do tempo, meninas e meninos do Ensino Fundamental passaram a ter destaque com suas contribuições, apresentando por vezes emoções afloradas em suas vozes. 
Diante das discussões sobre democracia na escola, o debate sobre o conteúdo do $\mathrm{CP}$ envolveu temas que abordavam questões polêmicas do cotidiano escolar que, por vezes, recebiam encaminhamentos diferenciados. O fio condutor do processo foi a busca de contribuições para a fluidez das ideias e de informações, o investimento na capacidade individual e coletiva de todos os envolvidos, o uso da análise crítica e da reflexão na construção e avaliação do processo democratizante, a preocupação com o bem estar do outro e do coletivo, bem como com a dignidade e os direitos de todos, com ênfase nas minorias (APPLE; BEANE, 2001, p. 17), tendo como pressuposto que a educação e a democracia são processos que demandam investimento no diálogo para a busca de consensos. Os temas elencados no CP foram:

- Entrada e saída da sala de aula e da escola;

- Como proceder mediante comportamentos inadequados na sala de aula;

- O uso da Tecnologia na sala de aula (Celular);

- Resolução de conflitos;

- Uso e conservação do espaço escolar;

- Como organizar as atividades coletivas de forma que os estudantes e os professores conheçam o que será realizado;

- O uso de drogas ilícitas;

- Funcionamento do Conselho de Classe e Série/Ano;

- Convivência em sala de aula e demais espaços da escola;

- Uso de livros paradidáticos;

- Funcionamento das instâncias deliberativas (Conselhos escolares);

- Discriminação e preconceito;

- Participação/contribuição dos estudantes na construção do currículo;

- Forma de abordagem de determinados temas com os estudantes do Ensino Fundamental (por ex. homofobia);

- Funcionamento e autonomia dos coletivos escolares;

- Diferentes formas de ensinar.

Questões polêmicas para o grupo como uso do celular na sala de aula, encaminhamentos sobre o uso de drogas ilícitas na escola, saída 
dos alunos da sala durante as aulas, discriminação e preconceito foram ilustrativas do exercício de diálogo, da revelação de posicionamentos distintos, bem como da busca do consenso e da construção de poder com o outro e não sobre o outro (PARO, 2008).

Esse rico exercício remeteu à necessidade da constituição de uma Comissão de Resolução de Conflitos (CRC), formada paritariamente por representantes de estudantes, funcionários, professores e pais que, a partir dos objetivos e princípios do projeto e da construção do $\mathrm{CP}$, ficaram encarregados de receber as demandas relacionadas aos conflitos, sistematizá-las, debatê-las e apresentar encaminhamentos mais ágeis à comunidade escolar.

Na reunião de avaliação das atividades de 2017, o grupo considerou que deveríamos dar continuidade ao projeto no ano de 2018, com o objetivo de implantar o CP e colocar em funcionamento a CRC.

Até junho de 2018 foram realizados quatro encontros, voltados à discussão e ao encaminhamento das demandas apresentadas com foco no cotidiano escolar, bem como realização de debate e reflexão sobre as nuances e dimensões das interferências externas a partir da Base Nacional Comum Curricular da Educação Infantil e Ensino Fundamental homologada em 20 de dezembro de 2017. A partir de meados deste ano, a CRC foi implementada. Os desdobramentos da atuação desta Comissão serão analisados em outra oportunidade por ser atividade ainda em desenvolvimento.

Uma questão importante que tem permeado a realização do projeto é a preocupação para que as práticas que são realizadas como parte dele sejam efetivamente incorporadas ao cotidiano escolar, de forma que haja mudanças mais permanentes no processo educativo da escola numa perspectiva democrática.

Espera-se que ao final do projeto, por parte da universidade, as velhas práticas que foram problematizadas e, em certa medida, superadas não sejam retomadas, dado que o desenvolvimento no projeto permitiu reflexões sobre as práticas educativas, ampliando a percepção sobre as dificuldades existentes em ouvir o outro, ainda mais quando este manifesta posições discordantes (APPLE; BEANE,2001).

Como fator que poderá contribuir para um constante movimento de busca por práticas democráticas, destacamos a realização de reflexões 
sobre as relações escolares entre os diferentes segmentos, professores/ alunos, alunos/funcionários, professores/equipe de gestão, bem como sobre as dificuldades muitas vezes presentes nas relações firmadas entre os pares, tal como já evidenciado por Castro (1998) quando afirma que a escola é um espaço permeado por relações de poder que, muitas vezes leva à submissão. Nesse sentido, foi importante, também, a contribuição de Paro (2008), que enfatiza a relevância da construção do poder com o outro e não sobre o outro, desencadeando o empoderamento do coletivo.

Ademais, a ampliação da percepção das pressões externas sofridas pela escola, especialmente no que se refere às imposições advindas da Secretaria de Estado da Educação (SEE/SP), foi bastante relevante, aspecto importante para seu enfrentamento, na perspectiva da resistência ativa, em que a escola constrói sua proposta educativa de forma que não fica à deriva dos vai-e-vem das políticas educacionais dos governantes, tal como evidenciado em Frigotto (2017).

\section{CONSIDERAÇÕES FINAIS}

A realização deste projeto de extensão, na forma de pesquisa-ação, aproximou a escola e a universidade, bem como os professores e os alunos no sentido do compartilhamento de saberes e experiências. Permitiu ainda a reflexão sobre a escola como instituição enrijecida, eivada por disputas de poder e, ao mesmo tempo, como espaço de possibilidades no que se refere ao avanço no estabelecimento de práticas democráticas.

Tais reflexões, estabelecidas no coletivo, evidenciaram limites e possiblidades na democratização das relações escolares, ao serem impulsionadas pela compreensão de que todos que trabalham e estudam na escola necessitam ser sujeitos de suas ações.

Como desafios para sua continuidade, tem-se a necessidade de se pensar e aprender modos que favoreçam a incorporação nas práticas escolares das regras de conduta estabelecidas no $\mathrm{CP}$, bem como sua permanente avaliação. Alguns temas levantados no primeiro ano do projeto, 2016, como a avaliação, precisam ser retomados no marco de uma ampla discussão sobre o Projeto Político Pedagógico, de forma que a democracia na escola seja eixo articulador da proposta educativa da escola.

Permanece ainda o desafio de engajamento dos pais e responsá- 
veis e dos funcionários de escola na construção e realização do projeto educativo da escola, e, também, como tem sido a relação entre os participantes dos encontros do projeto e seus pares considerando sua imbricação com questões de classe, gênero, ético raciais, geracionais trazidas pelos estudantes para o debate da construção de uma escola democrática.

Espera-se que esta experiência contribua com a ampliação do debate sobre democracia na sociedade, uma vez que a discussão e a vivência em experiências de gestão democrática do espaço escolar podem concorrer para fazer avançar a justiça social, ao ampliar a formação política dos envolvidos (BENEVIDES, 1994).

São grandes os desafios, já que a democracia será sempre delineada pelos condicionantes e determinantes da reprodução material (COUTINHO, 2000), e a escola é instituição que historicamente tem funcionado a partir de modelo que visa a submeter a todos a um mesmo padrão de conduta e pensamento (SACRISTÁN, 2001). No entanto, esses processos são contraditórios, e a realização do projeto, ainda em andamento, tem demonstrado a potência do debate coletivo na construção de propostas de gestão do espaço escolar pautada pelo diálogo, estudo e busca de consensos.

\section{REFERÊNCIAS}

ADRIÃO, T.; PERONI, V. Implicações do Programa Dinheiro Direto na Escola.Educação \& Sociedade, Campinas, SP,v.28,n.98,p. 253-267,jan./ abr. 2007.

APPLE, M.; BEANE, J. (orgs). Escolas democráticas. São Paulo: Cortez, 2001.

ARELARO, L. R. G.; JACOMINI, M. A.; CARNEIRO, S. R. G. Limitações da participação e gestão "democrática" na rede estadual paulista. Educação \& Sociedade, Campinas, v. 37, n. 137, p. 1143-1158, out./dez., 2006.

ARENDT, H. Entre o passado e o futuro. 6. ed. São Paulo: Perspectiva, 2009. 
BARBIER, R. A pesquisa-ação. Brasília: Liber Livro, 2007.

BENEVIDES, M. V. M. Cidadania e democracia. Lua Nova, n. 33 - 94, p. 5-16, 1994.

BOBBIO, N. O futuro da democracia. São Paulo: Paz e Terra, 2000.

BORDENAVE, J. E. D. O que é participação. Coleção Primeiros Passos. São Paulo: Brasiliense, 1983.

BORDIGNON, G. Gestão democrática da escola cidadã. In : FRIGOTTO, G.; CIAVATTA, M. (orgs.). Ensino Médio: ciência, cultura e trabalho. Brasília, DF: MEC/SEMTEC, 2004. p. 291-313.

BRASIL. Constituição da República Federativa do Brasil de 1988. Disponível em: http://www.planalto.gov.br/ccivil_03/constituicao/ constituicaocompilado.htm. Acesso em: 7 ago. 2018.

. Lei n 9.394, de 20 de dezembro de 1996. Estabelece as diretrizes e bases da educação nacional. Disponível em: http://www.planalto.gov. br/Ccivil_03/leis/L9394.htm. Acesso em: 7 ago. 2018.

CAMARGO, R. B.; ADRIÃO, T. A gestão democrática na Constituição Federal de 1988. In: ADRIÃO, T.; OLIVEIRA, R. P. (Org.). Gestão, Financiamento e Direito à Educação: Análise da LDB e da Constituição Federal. 2. ed. São Paulo: Xamã, 2002. p. 69-78.

CAMARGO, R. B. de; JACOMINI, M. A.; GOMES, M. de O. Desafios da gestão democrática na educação pública: 20 anos de LDB/96. Revista Eletrônica Pesquiseduca, Santos, v. 8, n. 16, p. 380-393, jul./dez. 2016.

CAMPOS, A. M.; MEDEIROS, J.; RIBEIRO, M. M. Escola em Luta. São Paulo: Veneta, 2016 (Coleção Baderna)

CÂNDIDO, A. A estrutura da escola. In: PEREIRA, L.; FORACCHI, M. A. Educação e Sociedade. 6. ed. São Paulo: Cia Editora Nacional, 1974, p. 107-128. 
CASTRO, M. Um estudo das relações de poder na escola pública de ensino fundamental à luz de Weber e Bourdieu: do poder formal, impessoal e simbólico ao poder explícito. Revista da Faculdade de Educação. São Paulo, v. 24 n. 1, p. 9-22, jan./jun. 1998.

COUTINHO, C. N. Contra a corrente: ensaios sobre democracia e socialismo. São Paulo: Cortez, 2000.

DOURADO, L. F. Políticas e gestão da educação básica no Brasil: limites e perspectivas. Educação e Sociedade, Campinas, SP, v. 28, n. 100, Especial, p. 921-946, 2007.

FREIRE, P. Política e educação. São Paulo: Cortez, 1993.

. Educação como prática da liberdade. 25. ed. São Paulo: Paz $\overline{\text { e Terra, } 2001 .}$

FRIGOTTO, G. (Org.). Escola "sem" partido: esfinge que ameaça a educação e a sociedade brasileira. Rio de Janeiro: Ed. da UERJ; Ed. da LPP, 2017. 144 p.

GRAMSCI, A. Cadernos do Cárcere, volume 2. Edição e tradução, Carlos Nelson Coutinho; coedição, Luiz Sérgio Henriques e Marco Aurélio Nogueira. 6. ed. Rio de Janeiro: Civilização Brasileira, 2011.

GIOVANNI, L. M. O papel dos professores e dos pesquisadores: um desafio no processo de pesquisa colaborativa. In: MARIN, A. J.; GIOVANNI, L. M.; GUARNIERI, M. R. Pesquisa com professores no início da escolarização. Araraquara, SP: Junqueira\&Marin; São Paulo: FAPESP, 2009.

PARO, V. H. Gestão escolar, democracia e qualidade do ensino. São Paulo: Ática, 2007.

. Educação como exercício de poder. São Paulo: Cortez, 2008.

. Crítica da estrutura da escola. São Paulo: Cortez, 2011. 
PEREIRA, L. Escola numa área metropolitana. Crise e racionalização de uma Empresa pública de Serviços. São Paulo: Pioneira/Edusp, 1967.

PERRELlA, C. dos S. S. Formação e participação políticas de conselheiros de escola: o caso do município de Suzano/SP (2005-2009). Tese (Doutorado em Educação). Faculdade de Educação da Universidade de São Paulo, 2012. 319p

SACRISTÁN, J. G. A educação obrigatória: seu sentido educativo e social. Porto Alegre: Artmed, 2001. 